\title{
In-situ generated palladium seeds lead to single-step bioinspired growth of AuePd bimetallic nanoparticles with catalytic performance
}

\author{
Sze-Ting Wong ${ }^{\text {a }}$, Mustaffa Shamsuddin ${ }^{\text {a, b, }}{ }^{*}$ Abdolhamid Alizadeh $^{\mathrm{c}^{* *}}{ }^{\text {and }}$ Yeoung-Sang Yun ${ }^{\mathrm{d}}$
}

\footnotetext{
${ }^{a}$ Department of Chemistry, Faculty of Science, Universiti Teknologi Malaysia, 81310, UTM Johor Bahru, Johor, Malaysia

${ }^{\mathrm{b}}$ Centre for Sustainable Nanomaterials, Ibnu Sina Institute for Scientific and Industrial Research, Universiti Teknologi Malaysia, 81310, UTM Johor Bahru, Johor, Malaysia

c Department of Chemistry, Nanoscience and Nanotechnology Research Center (NNRC), Razi University, Kermanshah, 67149, Iran

d Environmental Biotechnology National Research Laboratory, School of Chemical Engineering, Chonbuk National University, Jeonju, 561-756, Republic of Korea
}

\section{Abstract}

AuePd bimetallic nanospheres were synthesized via a green approach based on an in situ seed-mediated growth method using Etlingera elatior (EE) leaf extract as a bioreducing and capping agent. The synthesized bimetallic Au1Pd1, Au1Pd10, $\mathrm{Au} 10 \mathrm{Pd} 1$ and monometallic $\mathrm{Au}$ and $\mathrm{Pd}$ nanoparticles were characterized using various spectroscopic and microscopic techniques. This study reveals the morphology control of anisotropic Au nanoparticles, which can be achieved by the addition of palladium into the aqueous reaction mixture. Furthermore, the catalytic ability of each nanoparticle to catalyze the reduction of 4-nitrophenol to 4aminophenol were investigated. The bimetallic nanoparticles are more efficient in catalyzing the reduction of 4-nitrophenol than monometallic $\mathrm{Au}$ and $\mathrm{Pd}$ whereby the $\mathrm{Au}_{1} \mathrm{Pd}_{1}$ was the most efficient, with a rate constant, $\mathrm{k}$, of $24.0 \times 10^{-3} \mathrm{~min}^{-1}$.

Keywords: Alloys, Nanostructures, Electron microscopy, Energy dispersive analysis of X-rays. 